\title{
Exploring the Causes of Recruiting Failure
}

\author{
Linnan Sun \\ Management School, Jinan University, Guangzhou, China \\ Email: slnworld@163.com
}

Received 9 January 2015; accepted 25 January 2015; published 28 January 2015

Copyright (C) 2015 by author and Scientific Research Publishing Inc.

This work is licensed under the Creative Commons Attribution International License (CC BY).

http://creativecommons.org/licenses/by/4.0/

c) (i) Open Access

\begin{abstract}
With the continuous development of social economy, competition among enterprises has evolved into the talent competition. Talents as the important resource of the enterprises have drawn extensive attention. As an important access for the enterprises to absorb talents, recruiting is not only the important means of achieving human resources increase in an organization, but also ensuring the long development of the organization. However, the work of recruiting human resources in many enterprises are inefficient or ineffectiveness. Given this, this paper summarizes the views of recruiting effectiveness according to the related literatures domestic and abroad, and it analyzes four key causes of recruiting failure and provides corresponding solutions.
\end{abstract}

\section{Keywords}

Human Resources, Recruiting Failure, Recruiting Effectiveness, System Strategy

\section{Introduction}

In the 21st century, China entered a new stage of development. The international society, cultural diversity, economic globalization and information networking lead to fierce competition between different companies. In this new era of knowledge economy, the competition between enterprises actually manifests as strategic competition. Strategic competition depends on the resource competition and more important, the key role of resource competition is the human resource. To a great extent, the quality of human resources influences and even determines the success or failure of an organization. As Konosuke Matsushita [1] said, the premise of making machine manufacturing is to invest human resources. Panasonic's success is not due to its high quality products, but because it has the excellent staffs who can produce these required products. Under the impetus of the knowledge economy, with business and market environment changing rapidly, talents have become the important resource in the enterprise to obtain the core competitiveness.

More and more business operators realize that the nature of competition between enterprises is actually the power of internal human resources competition and the status of human resource management in enterprise is 
rising. As the first part of human resource management, recruitment is the first step to gain a competitive advantage. Recruitment is not only a measure to help organizations achieve human resource combination and replacement, but also an important magic weapon to achieve the company long-term development and strategic goals.

Through plenty of related literatures both domestic and abroad, this paper defines the effectiveness of human resource recruitment, and it analyzes the main causes of enterprise recruiting failure and bad influences. At the same time, the paper puts forward useful suggestions.

\section{Literature Reviews}

\subsection{The Progress of Foreign Research about Recruiting Effectiveness}

Recruitment is a process that the enterprise forecasts personnel needs and determines the qualification requirements according to the human resource planning and job analysis in order to meet organization demands of the survival and development. Then recruitment information is released to find and attract the candidates who have both abilities and interest to this organization. Finally, through scientific selection, the enterprise chooses the suitable talents and arranges them to meet organization's vacancy.

GE [2] is the earliest company with systematic evaluation of recruitment and it designed recruiting indexes to evaluate the effectiveness. Milkovich [3] pointed out that using the functions such as planning, implementation and coordination to continuously optimize recruitment is an effective recruitment process. This process to test the effectiveness of the enterprise recruitment work was mainly based on the cost, result, quality, channels and methods of recruitment. American management scientist Kleiman [4] summed up the 16 kinds of human resource management mode to improve the business performance and among them, the right way to select employees and placed them in the right jobs will largely improve the competitive power of organization. Hector [5] used a method of Utility Analysis to evaluate the effectiveness of recruitment. This method evaluated enterprise's recruitment work comprehensively from the aspects such as cost, quality and quantity of the applicants, which could find out the reasons for inefficiency and be perfected on the basis of the information feedback. Hinton [6] put forward the theory of recruitment risk, and he said through such means as background investigation or performance management can control the recruitment risk. Cook [7] put forward a way of contract in the hiring process to protect the interests of the applicants and enterprises. In the book "Recruitment Rules", Watson [8] pointed out that due to the existence of time delay between personnel demand confirmation and hiring the talents, the effective planning of personnel demand is very important.

\subsection{The Progress of Domestic Research about Recruiting Effectiveness}

Cao [9] pointed out that the important indicators of recruiting effectiveness included the cost, quantity and quality of the applicants. Wu [10] pointed out how the information asymmetry effected on human resource recruitment. This asymmetry not only reflects in the entire recruitment process, but also shows after arranging new employee orientation. In the paper "Five Pitfalls in the Recruitment”, Xing [11] found that some enterprises' recruiting foundation was weak, and human resource management has not got enough attention from managers. As a result, the companies could not complete the recruitment task efficiently.

Through the comprehensive view of scholars home and abroad, this paper summarizes the recruiting effectiveness as an evaluation standard or goal containing two steps: 1) Using the functions such as decision-making, organization, coordination and others to optimize the recruiting process; 2) Adjusting various recruiting resources reasonably to improve the recruiting efficiency and management level.

\section{Research on the Causes of Recruitment Failure and Solutions}

\subsection{The Lack of HRP (Human Resource Plan) and Recruiting Plan}

It's often said that preparedness ensures success, unpreparedness spells failure. HRP is a personnel overall plan which can ensure all the personnel decisions are consistent with the organization strategic goals. If there is no planning of human resource management, enterprise can't make the corresponding programmed response in advance in the face of some unexpected events. That is to say, the response is not initiative so that the enterprise will be forced into a passive position with many uncertainty risks and won't evade various crises timely, such as: 
the working schedules will be delay or change for the sudden understaffing; existing staff working efficiency will decrease because of huge working pressure.

\subsection{The Lack of the Choice of Recruiting Channels}

In the process of recruitment advertising, some companies will adopt amount of diverse recruitment ways in order to strengthen their propaganda, such as newspapers, multimedia and Internet. Those companies ignore the choice and cost efficiency, which causes amount of recruiting tasks and a series of waste.

Recruitment channels are divided into two kinds: the external and internal recruitment. The forms of internal recruitment are internal candidates, job rotation and recommending. For companies are very acquaint with their employees, the internal recruitment has a higher matching degree and recruiting efficiency. The forms of external recruitment are media advertising, employment agencies, headhunting companies, campus recruitment and network.

With the development of information technology, recruiting channels renovate increasingly and show their advantages. The organization should choose talent groups and recruiting channels based on various factors, such as human resource demand, or enterprise culture.

\subsection{The Lack of a Reasonable Personnel Test}

Information on the resumes is just the words about personal advantages, which may be exaggerated or false. Once reviewed the applicants' resumes, the next step is to select the best candidates for the job. "The best" is not to say that achievement is the highest, but to require that personal knowledge level, attitude, motivation and emotion could be matched with the job and organization's culture. Therefore, it needs some quantitative screening tools for objective evaluation of each candidate, such as paper test, assessment centers, and background checks. The reasonable personnel test should be both reliable and valid. Reliability is the test's first requirement and refers to its consistency [12]. Validity tells us whether the test is measuring what we think it's supposed to be measuring [13].

\subsection{The Lack of a Recruiting Feedback System}

When the company finds and hires the talents, recruiting is not over. We should look at the whole process of recruitment and analyze relevant data, such as the number of qualified candidates, the ratio of the actual employment number to the recruiting plan's number, the new employees' performance level and the rate of resignation. Through quantitative analysis, we could find the weak link during the recruiting. Setting up a recruiting feedback system is a continuous process of improvement.

\section{Conclusions}

The recruitment process is complex that includes multiple challenges, such as the shortage of viable candidates, the mismatching between talents and posts and the high quit rate of new employees. Given this, combined with various views of recruiting effectiveness domestic and abroad, this paper summarizes four key causes of recruiting failure:

1) Lacking of HRP (human resource plan) and recruiting plan.

2) Lacking of the choice of recruiting channels.

3) Lacking of a reasonable personnel test.

4) Lacking of a recruiting feedback system.

According to these four issues, the paper also analyzes the corresponding countermeasures, such as making recruitment plan, selecting the appropriate channels to choose talents, designing evaluation methods and setting up a recruiting feedback system. Among them, the most important is to build a concept of system strategy. Recruiting process contains a lot of steps and all the details are linked together, just as the old saying goes: a wrong act could causes loss of game.

\section{References}

[1] De, C. (2007) Japanese Management Systems. EMPH (Enterprise Management Publishing House), Beijing. 
[2] London EIU (2000) The Future Organizational Design. Xinhua Publishing House, Beijing.

[3] Milkovich, T.G. (2008) Compensation Management. China Renmin University Press Co. LTD, Beijing.

[4] Kleiman, S.L. (1999) HRM: A Management Tool for Competitive Advantage. CMP (China Machine Press), Beijing.

[5] Hector, B. (2006) Human Resource Management. Economy \& Management Publishing House, Beijing.

[6] Hinton, M. (2003) Managing the Human Resource Risk. Franchising World, 2, 58-60.

[7] Cook, G. (2001) The Strategy of the Human Resource. CMP, Beijing.

[8] Watson, M. (2007) Recruitment Rules. Cabinet Maker, 5535, 13-14.

[9] Cao, H.Y., Ye, W.L. and Li, S.G. (2005) Human Resources Management Theory and Practice. University of International Business and Economics Press, Beijing.

[10] Wu, Y.L., Ying, X.Y. and Wen, J.X. (2008) Virtual Management and Risk Avoidance of Enterprise Recruitment. Business Economic, 3, 82-84.

[11] Xing, J.L. (2007) Five Pitfalls in the Recruitment. Market Modernization, 10, 287.

[12] Murphy, K. and Davidshofer, D. (2001) Psychological Testing: Principles and Applications. Prentice Hall, Upper Saddle River, 73.

[13] Walsh, W.B. and Betz, N. (2001) Tests and Assessment. Prentice Hall, Upper Saddle River. 
Scientific Research Publishing (SCIRP) is one of the largest Open Access journal publishers. It is currently publishing more than 200 open access, online, peer-reviewed journals covering a wide range of academic disciplines. SCIRP serves the worldwide academic communities and contributes to the progress and application of science with its publication.

Other selected journals from SCIRP are listed as below. Submit your manuscript to us via either submit@scirp.org or Online Submission Portal.
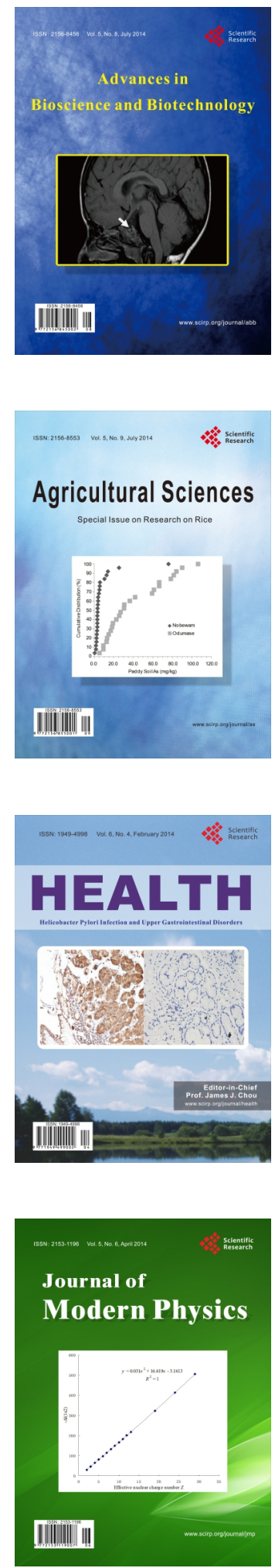
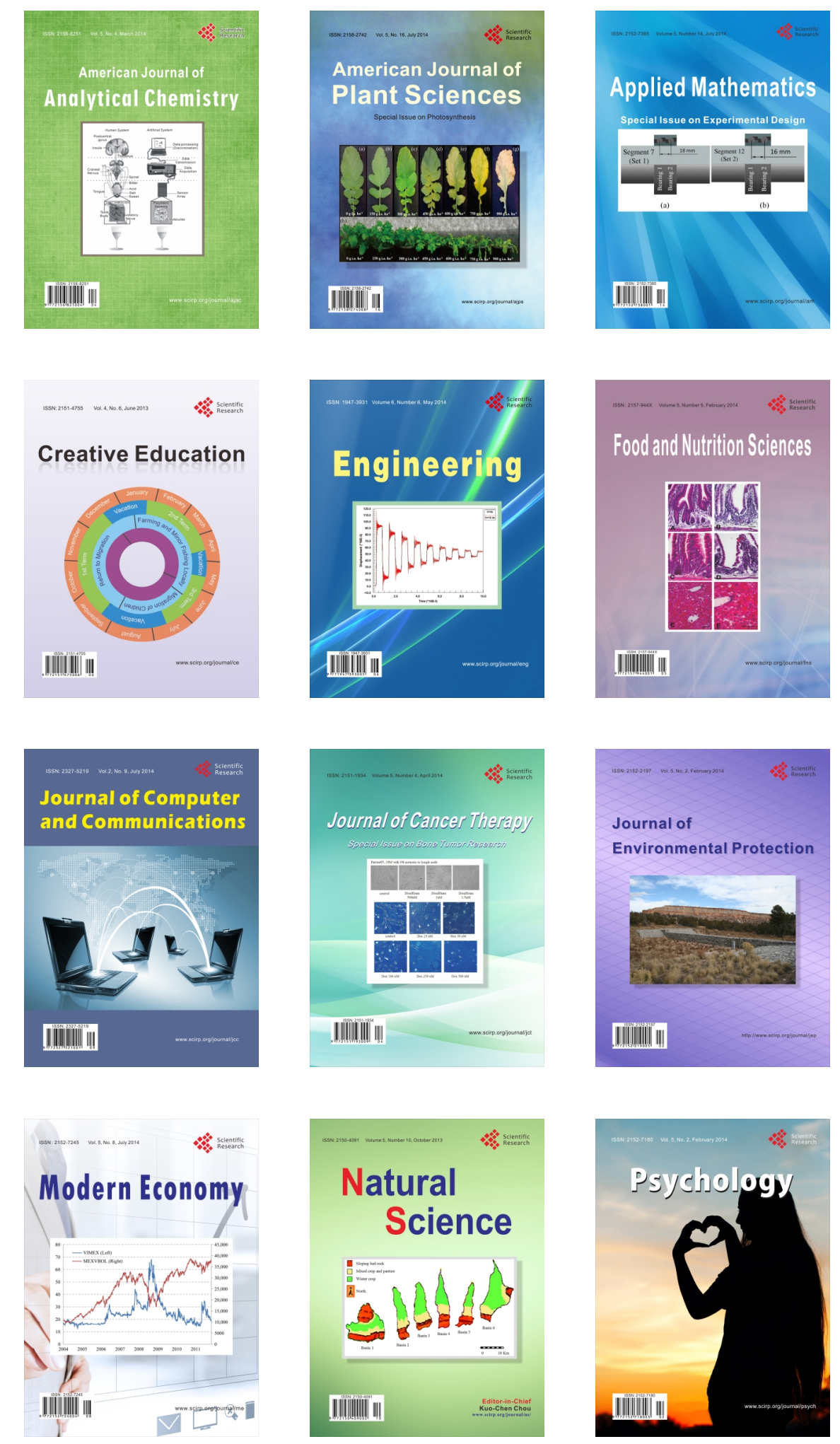